OPEN ACCESS

Edited by:

Clemens Mathias Rosenbaum, Asklepios Klinik Barmbek, Germany

Reviewed by:

Gianluigi Califano,

Federico II University Hospital, Italy Benedikt Becker,

Asklepios Klinik Barmbek, Germany

${ }^{*}$ Correspondence:

Jianlong Du

dj12021@sina.com

Specialty section:

This article was submitted to

Genitourinary Surgery,

a section of the journal

Frontiers in Surgery

Received: 06 November 2020 Accepted: 04 January 2021

Published: 28 January 2021

Citation:

Chen T, Zhu Z and Du J (2021) Efficacy of Intercostal Nerve Block for

Pain Control After Percutaneous

Nephrolithotomy: A Systematic

Review and Meta-Analysis.

Front. Surg. 8:623605.

doi: 10.3389/fsurg.2021.623605

\section{Efficacy of Intercostal Nerve Block for Pain Control After Percutaneous Nephrolithotomy: A Systematic Review and Meta-Analysis}

\author{
Tao Chen, ZhenQiang Zhu and Jianlong Du* \\ Department of Anesthesiology, Tongxiang First People's Hospital, Tongxiang, China
}

Background: We aimed to assess the efficacy of intercostal nerve block (ICNB) for pain relief after percutaneous nephrolithotomy (PCNL).

Methods: An electronic search of the databases of PubMed, Science Direct, BioMed Central, CENTRAL, Embase, and Google Scholar was conducted. All types of studies conducted on adult patients undergoing PCNL, comparing ICNB with control or any other anesthetic method, and reporting postoperative pain outcomes were included.

Results: Six studies were included. Studies compared ICNB with peritubal (PT) infiltration and with control. Pooled analysis of ICNB vs. PT infiltration indicated no difference between the two groups for pain scores at $6-8 \mathrm{~h}\left(\mathrm{MD}-0.44 ; 95 \% \mathrm{Cl}-3.41,2.53 ; \mathrm{l}^{2}=\right.$ $99 \% ; p=0.77), 12 \mathrm{~h}\left(\mathrm{MD}-0.98 ; 95 \% \mathrm{Cl}-4.90,2.94 ; \mathrm{l}^{2}=99 \% ; p=0.62\right)$ and $24 \mathrm{~h}$ (MD 0.16; 95\% Cl $-0.90,1.21 ; \mathrm{l}^{2}=88 \% ; p=0.77$ ). Time for first analgesic demand was also not significantly different between the two groups. Meta-analysis of ICNB vs. control indicated statistical significant difference in pain scores between the two groups at $8 \mathrm{~h}\left(\mathrm{MD}-1.55 ; 95 \% \mathrm{Cl}-2.60,-0.50 ; \mathrm{l}^{2}=47 \% ; p=0.04\right), 12 \mathrm{~h}(\mathrm{SMD}-2.49 ; 95 \%$ $\left.\mathrm{Cl}-4.84,-0.13 ; \mathrm{I}^{2}=96 \% ; p=0.04\right)$ and $24 \mathrm{~h}(\mathrm{SMD}-1.22 ; 95 \% \mathrm{Cl}-2.12,-0.32$; $\left.\mathrm{l}^{2}=88 \% ; p=0.008\right)$. The total analgesic requirement in morphine equivalents was not significantly different between the two groups.

Conclusions: ICNB may be effective in reducing postoperative pain after PCNL. However, its efficacy may not be greater than PT infiltration. Current evidence is from a limited number of studies. Further, high-quality randomized controlled trials are needed to provide robust evidence.

Keywords: nephrolithotomy, renal calculi, analgesia, pain, nerve block

\section{INTRODUCTION}

Percutaneous nephrolithotomy (PCNL) is a minimally invasive endourological procedure used to manage patients with large, multiple, and staghorn renal calculi (1). The procedure has a higher stone clearance rate as compared to extracorporeal shockwave lithotripsy, with significantly less morbidity as opposed to open surgery (2). However, significant post-operative pain can occur with PCNL in the first $24 \mathrm{~h}$ along the nephrostomy tract or due to dilatation of the renal capsule and parenchyma. Recent studies have reported that decreasing the size of the percutaneous tract 
(miniperc or small-bore PCNL) or completely avoiding the placement of the nephrostomy tube (tubeless PCNL) may help improve post-operative pain scores (3-5).

An alternate method of reducing pain is with the aid of analgesics or regional anesthetic techniques. Non-steroid antiinflammatory drugs (NSAIDs) and opioids may alleviate postoperative pain in PCNL patients but are associated with several adverse events. Regional anesthesia offers the advantage of direct action at the site of surgery with minimal adverse effects of analgesic drugs. Clinicians have also reported that peritubal (PT) infiltration of the nephrostomy tract with an anesthetic can reduce post-operative pain (6). Amongst nerve blocks, paravertebral, and intercostal nerve block (ICNB) are commonly used to provide post-operative pain relief after PCNL $(7,8)$.

The role of ICNB as a regional anesthesia technique is wellestablished in thoracic and abdominal surgery $(9,10)$. Some authors have also used ICNB for post-nephrectomy pain relief (11). The technique is easy to learn as the nerves travel in neurovascular bundles along the lower border of the ribs. There have been some concerns over complications like pneumothorax with ICNB but the overall incidence is low (12). A number of studies have assessed the efficacy of ICNB for providing pain relief after PCNL $(7,13)$, but to the best of our knowledge, no review has attempted to systematically analyze level- 1 evidence for its use. Therefore, the purpose of this study was to conduct a systematic literature search and collate data to assess the efficacy of ICNB for pain relief after PCNL.

\section{MATERIALS AND METHODS}

\section{Search Strategy}

We performed an electronic search of the databases of PubMed, Science Direct, BioMed Central, CENTRAL, Embase, and Google scholar. Databases were searched from inception to 1st July 2020. We used both MeSH terms and free-text keywords for searching relevant articles. Key-words used were, "percutaneous nephrolithotomy," "intercostal nerve block," "nerve block," "analgesia," and "anesthetic" in various combinations. The search strategy is presented as Supplementary Table S1. The reviewers screened the search results initially by their titles and abstracts for each database. After identifying potentially pertinent articles, full texts of the articles were extracted. Both the reviewers assessed individual articles based on the inclusion and exclusion criteria. Any disagreements were resolved by discussion. After screening, the bibliography of included studies and review articles on the subject were hand searched for any missed references. We conducted this review following the guidelines of the PRISMA statement (Preferred Reporting Items for Systematic Reviews and Meta-analyses) (14).

\section{Inclusion Criteria}

The Population, Intervention, Comparison, Outcome, and Study design (PICOS) framework was used to selection of studies. The review question of interest was: What is the efficacy of ICNB (Intervention) vs. control or any other anesthetic method (Comparison) for pain relief (Outcome) in adult patients undergoing PCNL (Population)?
For inclusion in the review, the population of the studies was to be adult patients ( $>18$ years) undergoing PCNL. Studies were to study ICNB as the Intervention and compare it with control or any other anesthetic method (Comparison). Outcomes of the study were to include postoperative pain and/or postoperative analgesic consumption. We included all types of studies in this review. Studies were included irrespective of sample size and the type of anesthetic agent used. No restriction was placed on the language of publication. We excluded single-arm studies and studies not reporting relevant data. Furthermore, case series, case reports, and review articles were also excluded.

\section{Data Extraction}

Following mutual agreement on the studies to be included, the two reviewers independently extracted data using a data extraction form. Details of study authors, publication year, study location, study type, sample size, demographic details, operation time, mean stone size/burden, ICNB protocol, control group protocol, and study outcomes were extracted. The primary outcome of interest in our analysis was post-operative pain. The secondary outcomes were total analgesic consumption, time to first analgesic demand, and complications. Outcome data was fed into meta-analysis software and cross-checked for correctness.

\section{Risk of Bias Assessment}

The Cochrane Collaboration risk assessment tool was used for assessing the quality of included studies (15). Two reviewers independently assessed each study. The following seven domains were used for quality assessment: random sequence generation, allocation concealment, blinding of participants and personnel, blinding of outcome assessment, incomplete outcome data, and selective reporting. The study was judged to have "high," "unclear," or "low" risk of bias for each domain. Any disagreements were resolved by discussion.

\section{Statistical Analysis}

"Review Manager" (RevMan, version 5.3; Nordic Cochrane Center [Cochrane Collaboration], Copenhagen, Denmark; 2014) was used for the meta-analysis. For this study, similar studies were grouped for the pooled analysis (ICNB vs. PT infiltration and ICNB vs. control). Since all outcomes were continuous variables, they were summarized using the mean difference (MD) with $95 \%$ confidence intervals (CI), if measured on the same scale. In case different scales were used, standardized mean difference (SMD) were calculated with 95\% CI. We used a random-effects model to calculate the pooled effect size for all our analyses. Heterogeneity was assessed using the $\mathrm{I}^{2}$ statistic. $\mathrm{I}^{2}$ values of $25-50 \%$ represented low, values of $50-75 \%$ medium, and more than $75 \%$ represented substantial heterogeneity. For studies not reporting continuous variables as median and interquartile range, mean and standard deviation scores were calculated using methods reported by Wan et al. (16). We used the software Engauge Digitizer to extract numerical data if only outcomes were reported only graphically. For total analgesic consumption, data on any other opioids were converted into morphine equivalents for the analysis (17). Due to the inclusion 

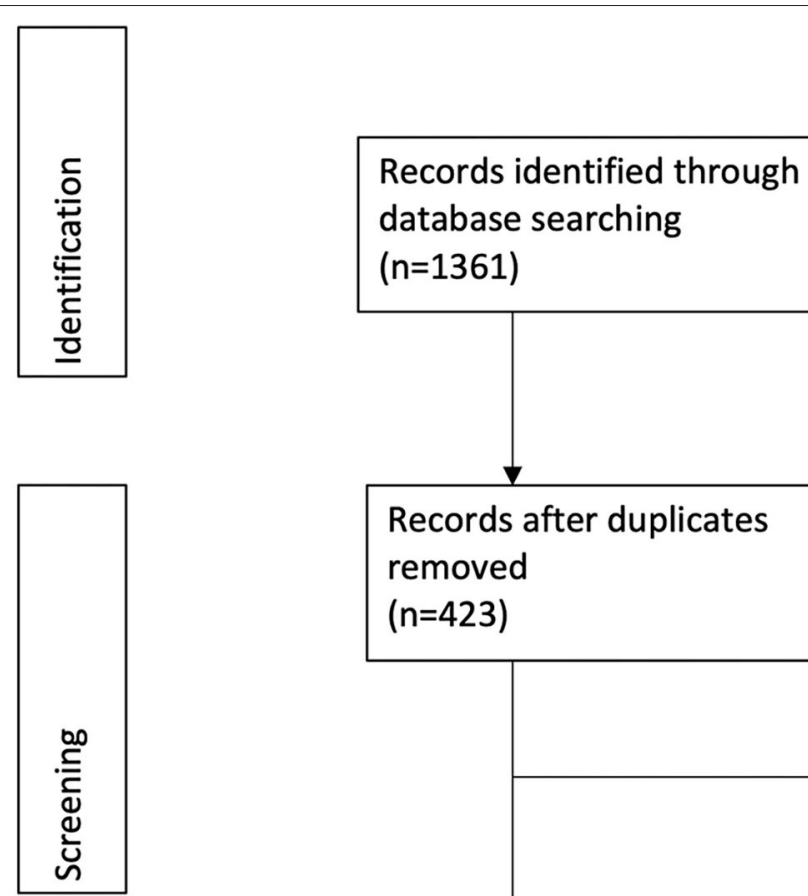

Records after duplicates removed $(n=423)$
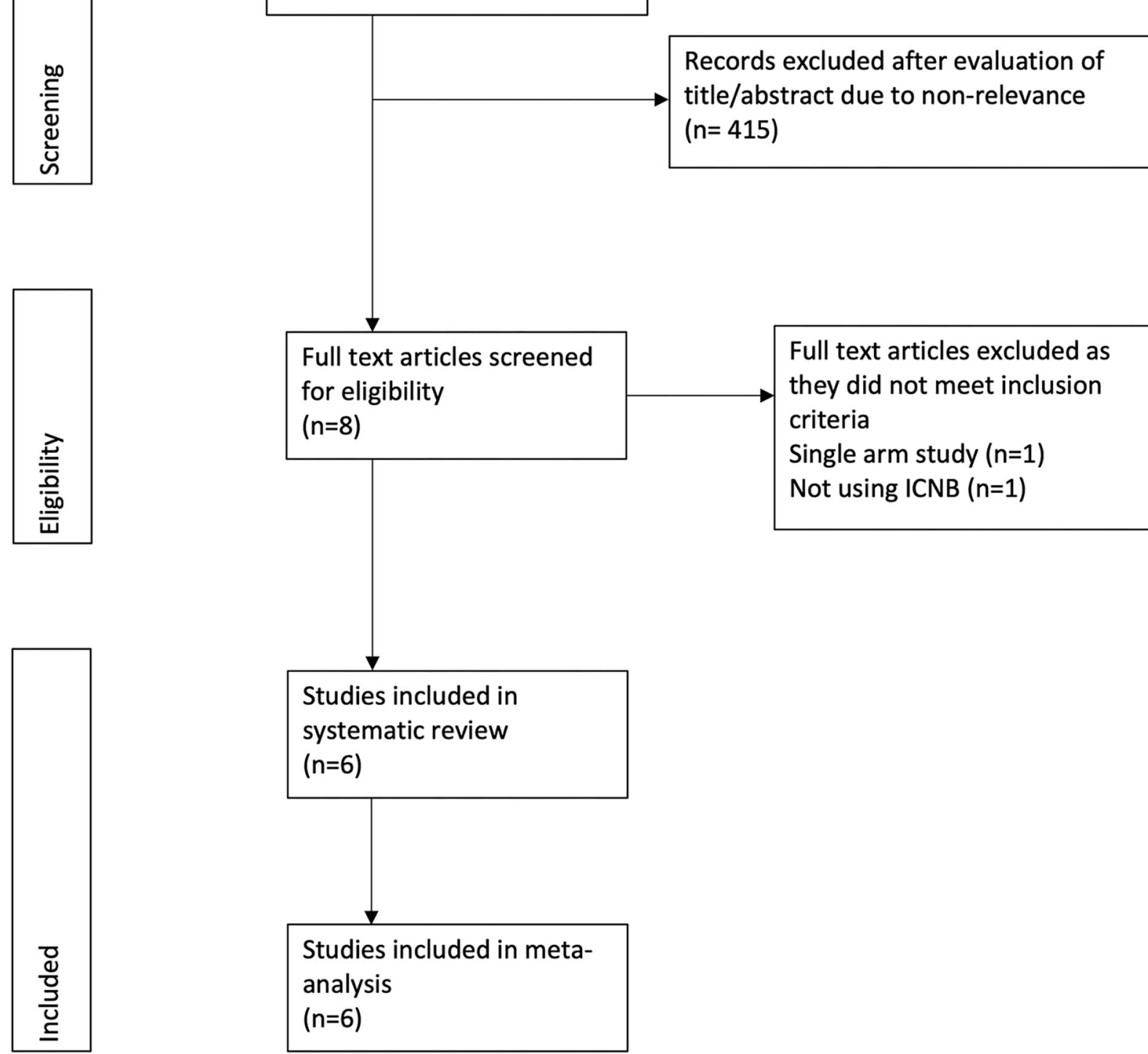

Studies included in systematic review $(n=6)$

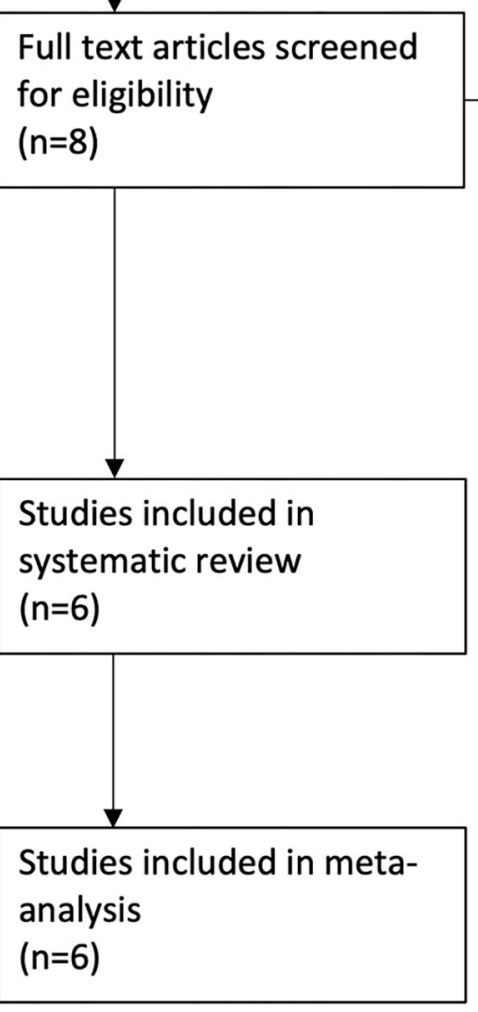

Full text articles excluded as they did not meet inclusion criteria Single arm study $(n=1)$ Not using ICNB $(n=1)$ 
TABLE 1 | Characteristics of included studies,

\begin{tabular}{|c|c|c|c|c|c|c|c|c|c|c|c|c|c|c|}
\hline \multirow[t]{2}{*}{ References } & \multirow[t]{2}{*}{ Location } & \multicolumn{2}{|c|}{ Sample size } & \multicolumn{2}{|c|}{ Mean age } & \multicolumn{2}{|c|}{ Male gender (\%) } & \multicolumn{2}{|c|}{ Operation time } & \multicolumn{2}{|c|}{$\begin{array}{l}\text { Mean stone size/burden } \\
(\mathrm{mm})\end{array}$} & \multirow[t]{2}{*}{ ICNB group } & \multirow[t]{2}{*}{ Control group } & \multirow[t]{2}{*}{$\begin{array}{l}\text { Nephrostomy } \\
\text { tube size }\end{array}$} \\
\hline & & ICNB & Control & ICNB & Control & ICNB & Control & ICNB & Control & ICNB & Control & & & \\
\hline Singh et al. (7) & India & 32 & 32 & $35.8 \pm 11.9$ & $36.9 \pm 11.3$ & $3 N R$ & NR & $\mathrm{NR}$ & NR & $19.1 \pm 5$ & $19.2 \pm 6$ & $\begin{array}{l}\text { At } 11 \text { th, } 12 \text { th rib } \\
\text { with } 10 \mathrm{~mL} \text { of } \\
0.25 \% \text { bupivacaine } \\
\text { at the end of the } \\
\text { procedure }\end{array}$ & $\begin{array}{l}\text { PT with } 10 \mathrm{cc} \text { of } \\
0.25 \% \text { bupivacaine }\end{array}$ & $24 \mathrm{~F}$ \\
\hline $\begin{array}{l}\text { Jonnavithula } \\
\text { et al. (18) }\end{array}$ & India & 26 & 30 & $41.3 \pm 13.4$ & $42.5 \pm 11.6$ & & 70 & $1.4 \pm 0.3 \mathrm{~h}$ & $1.5 \pm 0.2 \mathrm{~h}$ & NR & NR & $\begin{array}{l}\text { At } 10 \text { th, } 11 \text { th, } 12 \text { th } \\
\text { rib with } 15 \mathrm{~mL} \text { of } \\
0.5 \% \text { ropivacaine at } \\
\text { the end of the } \\
\text { procedure }\end{array}$ & $\begin{array}{l}\text { PT with } 5 \mathrm{~mL} \text { of } 0.5 \% \\
\text { ropivacaine }\end{array}$ & $\% 14 / 16 \mathrm{~F}$ \\
\hline Choi et al. (19) & Korea & 32 & I: 32 II: 32 & $254 \pm 16.2$ & $\begin{array}{l}\text { I: } 57.8 \\
\pm 13.8 \text { II: } \\
56.5 \pm 13\end{array}$ & 22 & I: 22 II: 22 & $\begin{array}{l}67.6 \pm \\
24.8 \mathrm{~min}\end{array}$ & $\begin{array}{l}\text { I: } 67.4 \pm 22.9 \mathrm{~min} \\
\text { II: } 78.5 \pm \\
41.4 \mathrm{~min}\end{array}$ & $302.9 \pm 138.6$ & $\begin{array}{l}\text { I: } 272.6 \pm 129 \text { II: } \\
270.2 \pm 144.4\end{array}$ & $\begin{array}{l}\text { At } 10 \text { th, } 11 \text { th, } 12 \text { th } \\
\text { rib with } 15 \mathrm{~mL} \text { of } \\
0.5 \% \text { ropivacaine } \\
\text { with epinephrine at } \\
\text { the end of the } \\
\text { procedure }\end{array}$ & $\begin{array}{l}\text { I: PT with } 20 \mathrm{~mL} \text { of } \\
0.25 \% \text { ropivacaine II: } \\
\text { No nerve block } \\
\text { or infiltration }\end{array}$ & Tubeless \\
\hline $\begin{array}{l}\text { Ozkan et al. } \\
\text { (20) }\end{array}$ & Turkey & 20 & 20 & $53 \pm 13.6$ & $57.3 \pm 7.4$ & 65 & 70 & $\begin{array}{l}74.4 \pm \\
23.6 \mathrm{~min}\end{array}$ & $76.5 \pm 25.4 \mathrm{~min}$ & $20 \pm 6.4$ & $17.5 \pm 7.5$ & $\begin{array}{l}\text { At } 11 \text { th, } 12 \text { th rib } \\
\text { with } 8 \mathrm{~mL} \text { of } 0.5 \% \\
\text { bupivacaine with } \\
\text { epinephrine before } \\
\text { the procedure }\end{array}$ & Sham block & Size NR \\
\hline $\begin{array}{l}\text { Honey et al. } \\
\text { (21) }\end{array}$ & Canada & 30 & 33 & $47.1 \pm 8.8$ & $48.7 \pm 13.7$ & 760 & 60.6 & NR & NR & $30.1 \pm 15.7$ & $28.3 \pm 12.3$ & $\begin{array}{l}2 \text { ribs above and } \\
\text { one rib below the } \\
\text { PCNL tract with } \\
20 \mathrm{~mL} \text { of } 0.5 \% \\
\text { bupivacaine with } \\
\text { epinephrine at the } \\
\text { end of the } \\
\text { procedure }\end{array}$ & Sham block & $\begin{array}{l}8.5 \mathrm{~F} / 6 \mathrm{~F} \text {, } \\
\text { internal. } \\
\text { external }\end{array}$ \\
\hline Viney et al. (13) & & 50 & 50 & $50 \pm N R$ & $48.9 \pm N R$ & 52 & 56 & $120 \mathrm{~min} \pm \mathrm{NR}$ & $115 \mathrm{~min} \pm \mathrm{NR}$ & NR & NR & $\begin{array}{l}\text { For three intercostal } \\
\text { nerves around the } \\
\text { PCNL site with } \\
\text { different anesthetic } \\
\text { agents at the end of } \\
\text { the procedure }\end{array}$ & I Control & Size NR \\
\hline
\end{tabular}

ICNB, Intercostal nerve block; NR, not reported; PCNL, percutaneous nephrolithotomy. 


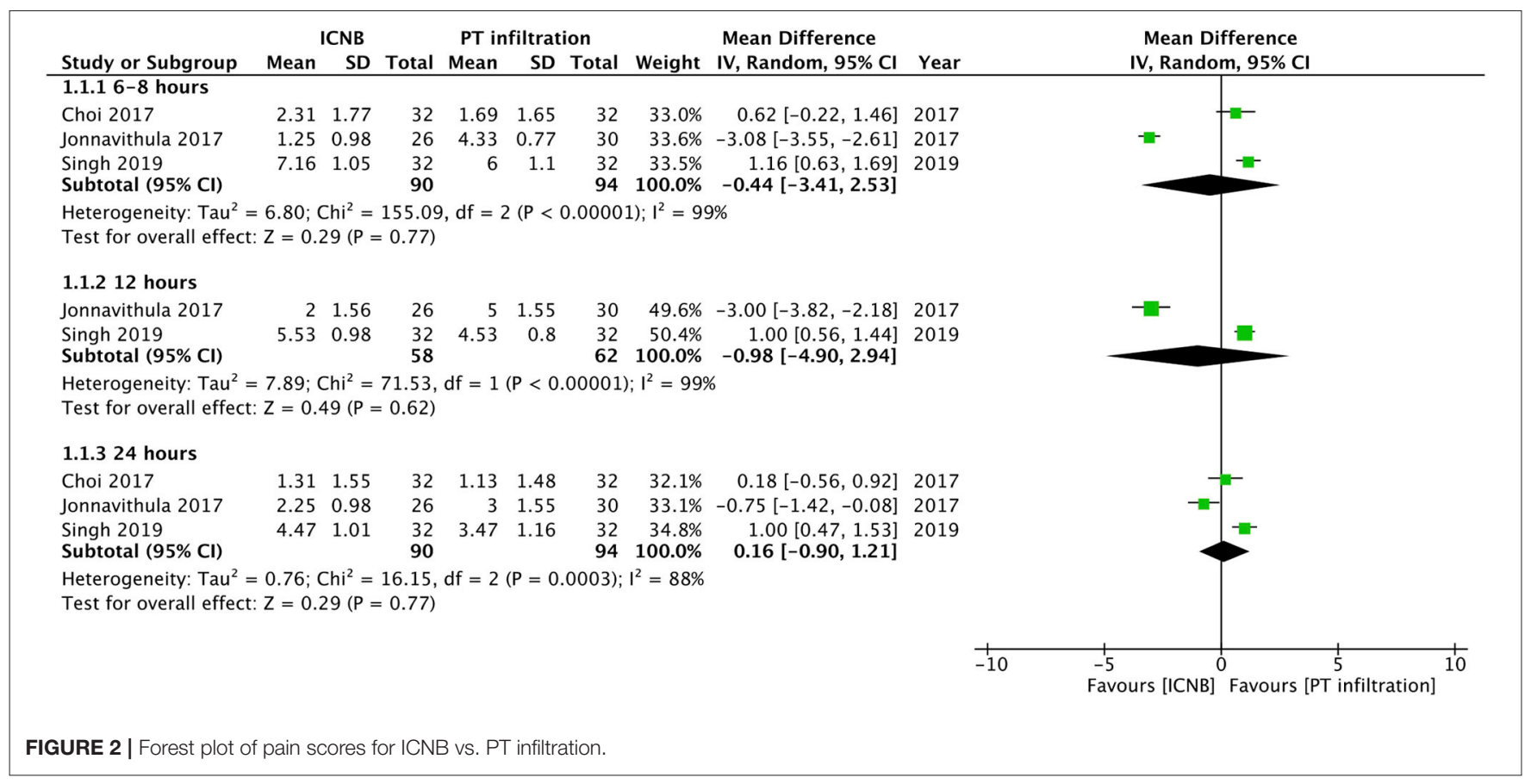

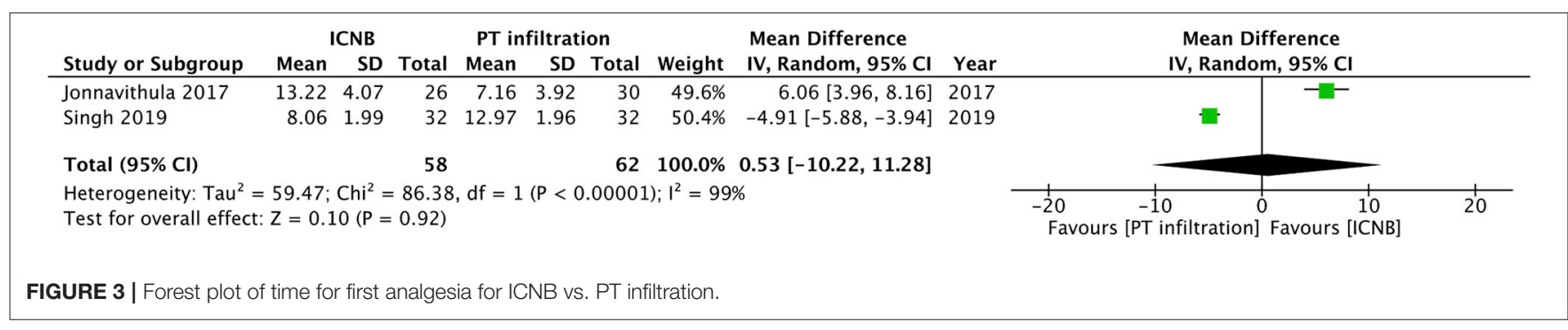

of fewer than 10 studies in the review, funnel plots were not used to assess publication bias.

\section{RESULTS}

The PRISMA flow-chart of the study is presented in Figure $\mathbf{1 .}$ A total of 423 unique records were examined. Eight full-texts were reviewed and a total of six studies included in the systematic review and meta-analysis $(7,13,18-21)$. Details of the included studies are presented in Table 1. Five were randomized controlled trials (RCTs) (7, 18-21) while one was a prospective nonrandomized study (13). The sample size of studies varied from 26-50 patients per arm. No statistically significant differences in baseline variables were reported by any of the included studies. Bupivacaine and ropivacaine were used for the ICNBs. Two studies $(7,18)$ compared ICNB with PT infiltration, three $(13,20,21)$ compared with control while one study (19) was a three-arm trial including ICNB, PT infiltration, and control. All studies administered ICNB after the procedure, except for Ozkan et al. (20).

\section{ICNB vs. PT Infiltration}

Three studies compared post-operative pain on Visual Analog Scale (VAS) between ICNB and PT infiltration. Pooled analysis of pain scores indicated no difference between the two groups at 6-8 h (MD - 0.44; 95\% CI -3.41, 2.53; $\left.\mathrm{I}^{2}=99 \% ; p=0.77\right), 12 \mathrm{~h}$ $\left(\mathrm{MD}-0.98 ; 95 \% \mathrm{CI}-4.90,2.94 ; \mathrm{I}^{2}=99 \% ; p=0.62\right)$ and $24 \mathrm{~h}$ (MD 0.16; 95\% CI $-0.90,1.21 ; \mathrm{I}^{2}=88 \% ; p=0.77$ ) (Figure 2). Time for first analgesic demand in hours was reported by two trials. Meta-analysis indicated no statistical significant differences between the two groups ( $\mathrm{MD}-0.53$; $95 \% \mathrm{CI}-10.22,11.28 ; \mathrm{I}^{2}=$ 99\%; $p=0.92$ ) (Figure 3).

Singh et al. (7) analyzed the total diclofenac use between ICNB and PT infiltration groups. The reported a higher total analgesic consumption in patients receiving ICNB as compared to PT infiltration $(p<0.001)$. On the other hand, Choi et al. (19) reported a trend toward lower analgesic consumption (fentanyl) with ICNB as compared to PT infiltration but the result was not statistically significant $(p=0.07)$. None of the studies reported any complications attributable to ICNB or PT infiltration. 


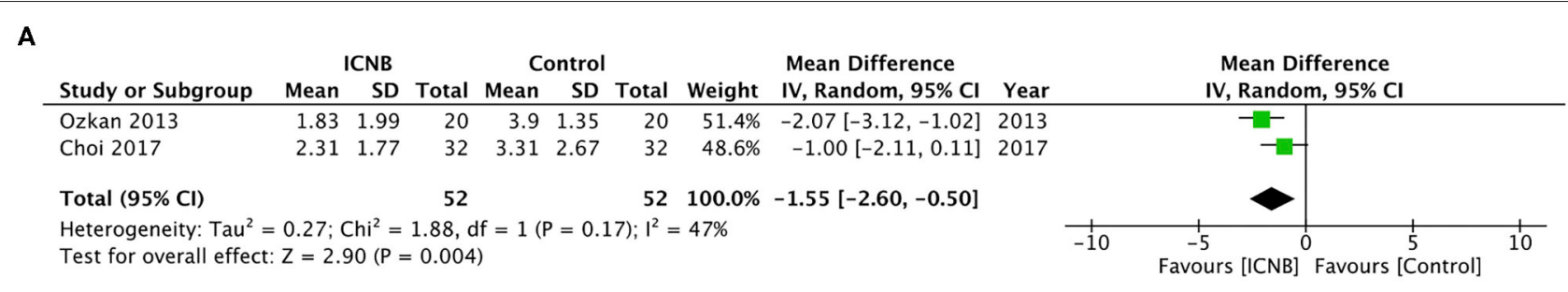

B

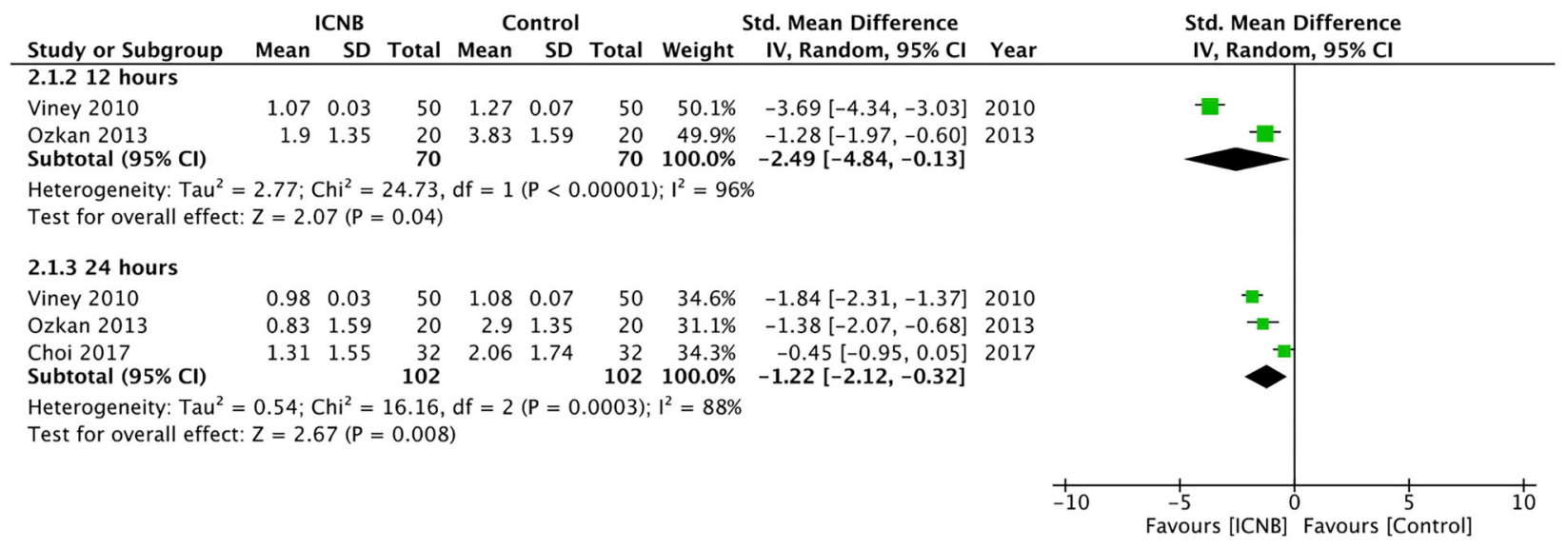

FIGURE 4 | Forest plot of pain scores for ICNB vs. control. (A) 8 h (B) 12 and 24 h.

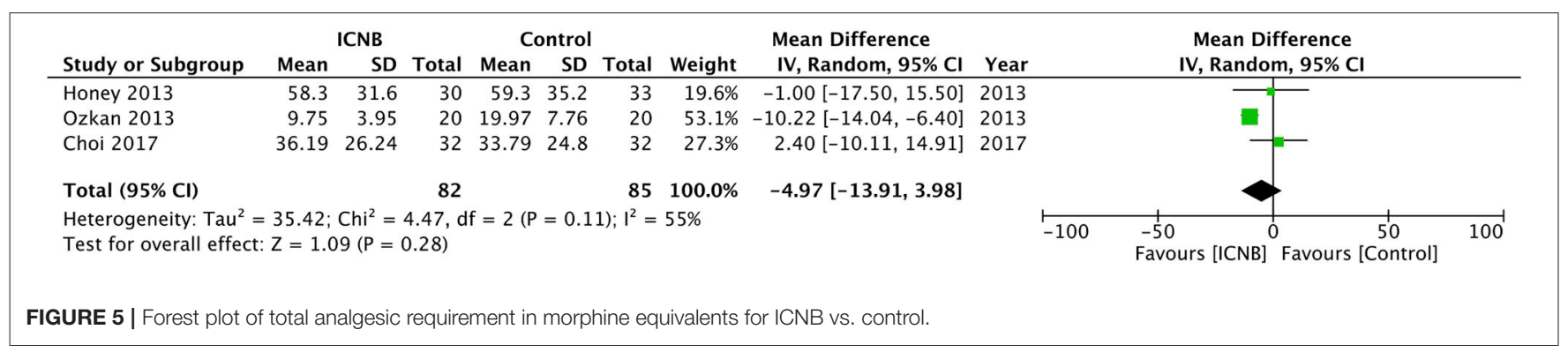

\section{ICNB vs. Control}

A total of four studies compared outcomes of ICNB with a sham block or no nerve block. Two studies reported postoperative pain outcomes on the VAS scale while one study measured it on a three-point scale. Meta-analysis indicated statistical significant difference in pain scores between the two groups at $8 \mathrm{~h}\left(\mathrm{MD}-1.55 ; 95 \% \mathrm{CI}-2.60,-0.50 ; \mathrm{I}^{2}=47 \% ; p=\right.$ 0.04) (Figure 4A), $12 \mathrm{~h}$ (SMD -2.49; 95\% CI $-4.84,-0.13$; $\left.\mathrm{I}^{2}=96 \% ; p=0.04\right)$ and $24 \mathrm{~h}(\mathrm{SMD}-1.22 ; 95 \% \mathrm{CI}-2.12$, $-0.32 ; \mathrm{I}^{2}=88 \% ; p=0.008$ ) (Figure $4 \mathbf{B}$ ). Data on the total analgesic requirement in morphine equivalents were pooled from three studies. Two studies reported converted total morphine equivalents themselves, while conversion was required for the study of Ozkan et al. (20). Results indicated no statistical significant difference between the two groups (MD -4.97; 95\% CI $-13.91,3.98 ; \mathrm{I}^{2}=55 \% ; p=0.28$ ) (Figure 5). Viney et al. (13) in their study reported decreased requirement of analgesics in patients receiving ICNB as compared to controls but their results were not statistically significant. Since the study did not report standard deviation scores of the required data, it was not included in this meta-analysis. Time for the first analgesic was not reported by any trial. No study reported complications attributable to ICNB.

\section{Risk of Bias Analysis}

The authors' assessment of the risk of bias in the included studies is presented in Figure 6. Adequate methods of randomization were described in four studies $(7,18-20)$. Appropriate methods of blinding of both participants and outcome assessors were reported by two studies $(19,20)$. Reporting bias was low with the three $\operatorname{RCTs}(7,18,20)$ which were pre-registered.

\section{DISCUSSION}

Since its first description, PCNL has practically replaced open surgery for the management of large renal calculi $(22,23)$. Studies 


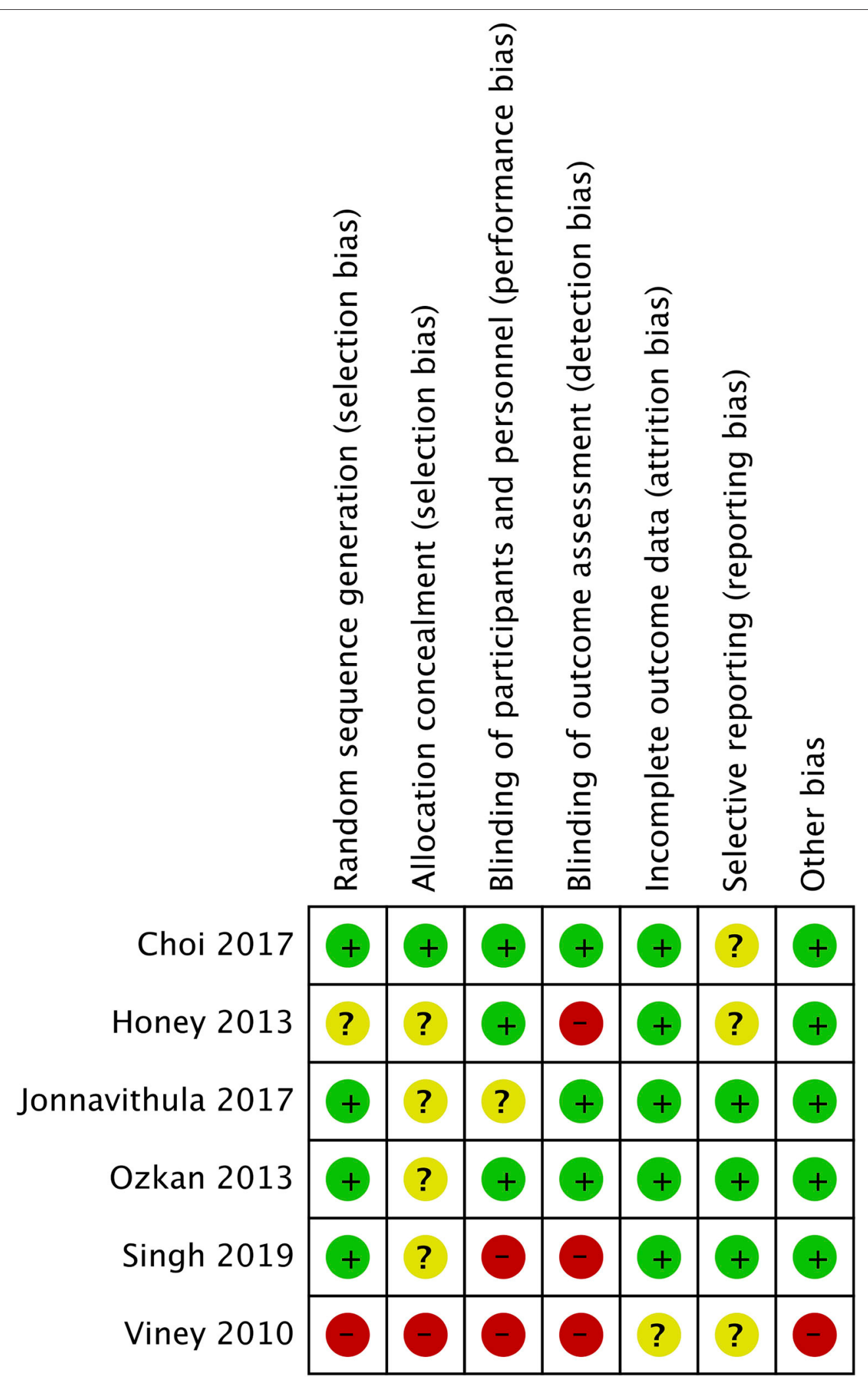

FIGURE 6 | Risk of bias analysis. 
have reported a high stone clearance rate of $>90 \%$ with PCNL $(24,25)$. As compared to open surgery, PCNL is associated with reduced operative times, decreased blood loss, shorter hospital stay, and reduced overall complications (23). However, pain after PCNL can be a significant problem in the early postoperative period. No standard published guidelines exists for pain management after PCNL. Clinicians have reportedly used the inter-pleural block, renal capsular block, paravertebral block, and ICNB with varying success $(7,8,26,27)$. While a recent meta-analysis has indicated that paravertebral block is effective in pain management (23), no review has synthesized evidence on the efficacy of ICNB for PCNL to date.

Subcutaneous infiltration of the surgical site with a local anesthetic is a common practice in several surgical specialties, however, its role in PCNL is questionable (28). However, PT infiltration along the entire length of the nephrostomy tract has shown benefits for post-operative analgesia $(29,30)$. In our analysis comparing ICNB with PT infiltration, we did not find any statistically significant differences between the two techniques for pain scores or time for first analgesic demand. On examination of the forest plots, the study of Jonnavithula et al. (18) was found to favor ICNB while opposite results were reported by Singh et al. (7). Choi et al. (19), on the other hand, found no difference between the two groups. Such variation may be attributed to procedural differences between the three studies. A nephrostomy tube is often inserted after PCNL for unimpeded drainage of the pelvicalyceal system. Studies have reported that smaller tubes are associated with reduced pain $(31,32)$. In the study of Jonnavithula et al. (18) smaller bore sizes were used as opposed to $24 \mathrm{~F}$ tube size in the study of Singh et al. (7). Choi et al. (19) conducted their study on tubeless PCNL. The extent of anesthesia provided by ICNB extends only up to the lateral cutaneous branches of the inter-costal nerves which innervate the access site of PCNL (33). The nerve supply of the deeper abdominal viscera is dependent on the celiac plexus (34). Thus, it may be postulated that in the study of Singh et al. (7) using larger nephrostomy tubes, PT infiltration may have provided better analgesia due to direct action of the anesthetic along the entire nephrostomy tract. This effect may have not been significant in the remaining two studies with tubeless (19) or small-bore PCNL (18).

In the second part of our study, we compared outcomes of ICNB with control and found significantly reduced pain scores in patients receiving ICNB at 8,12 , and $24 \mathrm{~h}$. However, the total analgesic requirement was not significantly different between the two groups. It is important to note that the effect size for pain scores at all three time intervals was small with the upper end of $95 \%$ CI very close to 0 . Similar small effect sizes have been reported by Tan et al. (8) in their meta-analysis of paravertebral blocks for PCNL (Analgesic requirement: SMD -1.55 ; 95\% CI -2.18, -0.92). In comparison with other surgeries, Detterbeck et al. (35) in a systematic review have reported significantly better outcomes with ICNB as compared to oral analgesics for thoracotomy patients. Their study indicated that continuous ICNB with a catheter can provide better results as compared to single ICNB. While catheter placement may be feasible in thoracotomy where surgical access is available, it may significantly increase morbidity after PCNL (13). Furthermore, being a minimally invasive procedure, pain intensity, and duration after PCNL is comparatively less.

As with any regional anesthesia procedure, ICNB may also result in complications. Experimental studies on healthy volunteers have indicated reduced vital capacity with ICNB (36), but these results have not been corroborated by other studies (37). Other complications with ICNB may include pneumothorax, pleural effusions, abscess formation, neuritis, and hypotension. The reported incidence of pneumothorax with ICNB has been quite variable ranging from 0.073 to $19 \%$ (38). In our review, none of the included studies reported any complication attributable to ICNB. This may be due to the limited sample size of all included trials.

Our review has some limitations. Foremost, a limited number of studies with small sample size were available for data analysis in our review. Secondly, there were inter-study methodological differences that may have contributed to the high heterogeneity in our analysis. There were differences in the anesthetic agents, the use of epinephrine, utilization and size of nephrostomy tubes, mean stone size/burden, number of nerves blocked, timing of ICNB etc. These may have skewed results of our analysis. Due to lack of comparative studies between ropivacaine and bupivacaine for ICNB, our study could not comment on the superiority of one agent over the other. However, both ropivacaine and bupivacaine are long-acting anesthetic agents with similar pharmacokinetic properties (39). Comparative studies for other regional anesthesia techniques have indicated no difference between the two agents $(39,40)$. Lastly, the outcomes of any regional anesthesia technique are also dependent on the skill of the operator and the pain threshold of the patient. These factors could not be accounted for in our review.

To conclude, the results of our study indicate that ICNB may be effective in reducing postoperative pain scores in patients undergoing PCNL. However, its efficacy may not be $>$ PT infiltration. Current evidence is from a limited number of studies. There is a need for further trials with large sample size comparing ICNB with control and PT infiltration to establish high-quality evidence.

\section{DATA AVAILABILITY STATEMENT}

The original contributions generated for this study are included in the article/Supplementary Material, further inquiries can be directed to the corresponding author/s.

\section{AUTHOR CONTRIBUTIONS}

TC conceived, designed the study, and involved in the writing of the manuscript. ZZ and JD collected the data, and performed the literature search. All authors have read and approved the final manuscript. 


\section{FUNDING}

This study was supported by Clinical Research Project of Zhejiang Medical Association (2017ZYC-A86) and Tongxiang Science and Technology Plan Project (201702078).

\section{REFERENCES}

1. Ferakis N, Stavropoulos M. Mini percutaneous nephrolithotomy in the treatment of renal and upper ureteral stones: lessons learned from a review of the literature. Urol Ann. (2015) 7:141-8. doi: 10.4103/0974-7796.152927

2. Weiland D, Pedro RN, Anderson JK, Best SL, Lee C, Hendlin K, et al. Randomized prospective evaluation of nephrostomy tube configuration: impact on postoperative pain. Int Braz J Urol. (2007) 33:313-22. doi: 10.1590/S1677-55382007000300003

3. Choi SW, Kim KS, Kim JH, Park YH, Bae WJ, Hong SH, et al. Totally tubeless versus standard percutaneous nephrolithotomy for renal stones: analysis of clinical outcomes and cost. J Endourol. (2014) 28:148794. doi: 10.1089/end.2014.0421

4. Xun Y, Wang Q, Hu H, Lu Y, Zhang J, Qin B, et al. Tubeless versus standard percutaneous nephrolithotomy: an update meta-analysis. BMC Urol. (2017) 17:102. doi: 10.1186/s12894-017-0295-2

5. Kim BS. Recent advancement or less invasive treatment of percutaneous nephrolithotomy. Korean J Urol. (2015) 56:61423. doi: 10.4111/kju.2015.56.9.614

6. Nirmala J, Kumar A, Devraj R, Vidyasagar S, Ramachandraiah G, Murthy PVLN. Role of buprenorphine in prolonging the duration of post-operative analgesia in percutaneous nephrolithotomy: comparison between bupivacaine versus bupivacaine and buprenorphine combination. Indian J Urol. (2015) 31:132-5. doi: 10.4103/0970-1591.152815

7. Singh I, Yadav O, Gupta S. Efficacy of intercostal nerve block with $0.25 \%$ bupivacaine in percutaneous nephrolithotomy: a prospective randomized clinical trial. Urol Ann. (2019) 11:363-8. doi: 10.4103/UA.UA_141_18

8. Tan X, Fu D, Feng W, Zheng X. The analgesic efficacy of paravertebral block for percutaneous nephrolithotomy: a metaanalysis of randomized controlled studies. Med (United States). (2019) 98:e17967. doi: 10.1097/MD.0000000000017967

9. Miller I. Intercostal nerve block. Aust Fam Physician. (1984) 13:864-6. Available online at: http://www.ncbi.nlm.nih.gov/pubmed/6084506 (accessed August 10, 2020).

10. Kopacz DJ, Thompson GE. Intercostal nerve block. In: Waldman SD, Bloch JI, editors. Pain Management. 1st ed. Philadelphia, PA: Saunders (2007). p. 1250-8. doi: 10.1016/B978-0-7216-0334-6.50153-9

11. RIichardson J, Sabanathan S. Thoracic paravertebral analgesia. Acta Anaesthesiol Scand. (1995) 39:100515. doi: 10.1111/j.1399-6576.1995.tb04219.x

12. Knowles P, Hancox D, Letheren M, Eddleston J. An evaluation of intercostal nerve blockade for analgesia following renal transplantation. Eur J Anaesthesiol. (1998) 15:457-61. doi: 10.1097/00003643-199807000-00012

13. Viney R, Garston H, Patel P, Devarajan R. Perioperative intercostal nerve blockade in percutaneous nephrolithotomy a comparative cohort study. J Clin Urol. (2010) 3:106-10. doi: 10.1016/j.bjmsu.2010.02.001

14. Moher D, Liberati A, Tetzlaff J, Altman DG, PRISMA Group. Preferred reporting items for systematic reviews and meta-analyses: the PRISMA statement. PLoS Med. (2009) 6:e1000097. doi: 10.1371/journal.pmed.1000097

15. Higgins J, Thomas J, Chandler J, Cumpston M, Li T, Page M, et al. Cochrane Handbook for Systematic Reviews of Interventions. Version 6. Cochrane (2019). doi: 10.1002/9781119536604. Available online at: www.training.cochrane.org/ (accessed October 1, 2020)

16. Wan X, Wang W, Liu J, Tong T. Estimating the Sample Mean and Standard Deviation From the Sample Size, Median, Range and/or Interquartile Range. (2014). Available online at: http://www.biomedcentral.com/1471-2288/14/ 135 (accessed February 25, 2020).

17. Washington State Agency Medical Directors' Group. Opioid Dose Calculator. Available online at: http://www.agencymeddirectors.wa.gov/Calculator/ DoseCalculator.htm (accessed August 10, 2020).

\section{SUPPLEMENTARY MATERIAL}

The Supplementary Material for this article can be found online at: https://www.frontiersin.org/articles/10.3389/fsurg. 2021.623605/full\#supplementary-material

18. Jonnavithula N, Chirra RR, Pasupuleti SL, Devraj R, Sriramoju V, Pisapat $\mathrm{MV}$. A comparison of the efficacy of intercostal nerve block and peritubal infiltration of ropivacaine for post-operative analgesia following percutaneous nephrolithotomy: a prospective randomised double-blind study. Indian J Anaesth. (2017) 61:655-60. doi: 10.4103/ija.IJA_88_17

19. Choi SW, Cho SJ, Moon HW, Lee KW, Lee SH, Hong SH, et al. Effect of intercostal nerve block and nephrostomy tract infiltration with ropivacaine on postoperative pain control after tubeless percutaneous nephrolithotomy: a prospective, randomized, and case-controlled trial. Urology. (2018) 114:4955. doi: 10.1016/j.urology.2017.12.004

20. Ozkan D, Akkaya T, Karakoyunlu N, Arik E, Ergil J, Koc Z, et al. Effect of ultrasound-guided intercostal nerve block on postoperative pain after percutaneous nephrolithotomy: prospective randomized controlled study. Anaesthesist. (2013) 62:988-94. doi: 10.1007/s00101-013-2253-Z

21. Honey RJDA, Ghiculete D, Ray AA, Pace KT. A randomized, doubleblinded, placebo-controlled trial of intercostal nerve block after percutaneous nephrolithotomy. J Endourol. (2013) 27:415-9. doi: 10.1089/end.2012.0418

22. Fernstrom I, Johansson B. Percutaneous pyelolithotomy. Scand J Urol Nephrol. (1976) 10:257-9. doi: 10.1080/21681805.1976.11882084

23. Chen Y, Feng J, Duan H, Yue Y, Zhang C, Deng T, et al. Percutaneous nephrolithotomy versus open surgery for surgical treatment of patients with staghorn stones: a systematic review and meta-analysis. PLoS ONE. (2019) 14:e0206810. doi: 10.1371/journal.pone.0206810

24. Mandal S, Goel A, Kathpalia R, Sankhwar S, Singh V, Sinha RJ, et al. Prospective evaluation of complications using the modified Clavien grading system, and of success rates of percutaneous nephrolithotomy using Guy's Stone Score: a single-center experience. Indian J Urol. (2012) 28:3928. doi: 10.4103/0970-1591.105749

25. Kumar U, Tomar V, Yadav SS, Priyadarshi S, Vyas N, Agarwal N, et al. STONE score versus Guy's Stone Score - Prospective comparative evaluation for success rate and complications in percutaneous nephrolithotomy. Urol Ann. (2018) 10:76-81. doi: 10.4103/UA.UA_119_17

26. Dalela D, Goel A, Singh P, Shankhwar SN. Renal capsular block: a novel method for performing percutaneous nephrolithotomy under local anesthesia. J Endourol. (2004) 18:544-6. doi: 10.1089/end.2004.18.544

27. Trivedi NS, Robalino J, Shevde K. Interpleural block: a new technique for regional anaesthesia during percutaneous nephrostomy and nephrolithotomy. Can J Anaesth. (1990) 37:479-81. doi: 10.1007/BF03005632

28. Haleblian GE, Sur RL, Albala DM, Preminger GM. Subcutaneous bupivacaine infiltration and postoperative pain perception after percutaneous nephrolithotomy. J Urol. (2007) 178:925-8. doi: 10.1016/j.juro.2007.05.025

29. Shah HN, Shah RH, Sodha HS, Khandkar AA, Gokhale A. A randomized control trial evaluating efficacy of nephrostomy tract infiltration with bupivacaine after tubeless percutaneous nephrolithotomy. J Endourol. (2012) 26:478-83. doi: 10.1089/end.2011.0465

30. Wang J, Zhang C, Tan D, Tan G, Yang B, Chen W, et al. The effect of local anesthetic infiltration around nephrostomy tract on postoperative pain control after percutaneous nephrolithotomy: a systematic review and metaanalysis. Urol Int. (2016) 97:125-33. doi: 10.1159/000447306

31. De Sio M, Autorino R, Quattrone C, Giugliano F, Balsamo R, D’Armiento M. Choosing the nephrostomy size after percutaneous nephrolithotomy. World J Urol. (2011) 29:707-11. doi: 10.1007/s00345-010-0587-6

32. Cormio L, Preminger G, Saussine C, Buchholz NP, Zhang X, Walfridsson $\mathrm{H}$, et al. Nephrostomy in percutaneous nephrolithotomy (PCNL): does nephrostomy tube size matter? Results from The Global PCNL Study from The Clinical Research Office Endourology Society. World J Urol. (2013) 31:1563-8. doi: 10.1007/s00345-012-0969-z

33. Court C, Vialle R, Lepeintre JF, Tadié M. The thoracoabdominal intercostal nerves: an anatomical study for their use in neurotization. Surg Radiol Anat. (2005) 27:8-14. doi: 10.1007/s00276-004-0281-8 
34. Rana MV, Candido KD, Raja O, Knezevic NN. Celiac plexus block in the management of chronic abdominal pain. Curr Pain Headache Rep. (2014) 18:394. doi: 10.1007/s11916-013-0394-Z

35. Detterbeck FC. Efficacy of methods of intercostal nerve blockade for pain relief after thoracotomy. Ann Thorac Surg. (2005) 80:1550-9. doi: 10.1016/j.athoracsur.2004.11.051

36. Jakobson S, Ivarsson I. Effects of intercostal nerve blocks (Bupivacaine $0.25 \%$ and Etidocaine $0.5 \%$ ) on chest wall mechanics in healthy men. Acta Anaesthesiol Scand. (1977) 21:489-96. doi: 10.1111/j.1399-6576.1977.tb01250.x

37. Hecker BR, Bjurstrom R, Schoene RB. Effect of intercostal nerve blockade on respiratory mechanics and $\mathrm{CO} 2$ chemosensitivity at rest and exercise. Anesthesiology. (1989) 70:13-8. doi: 10.1097/00000542-198901000-00005

38. Shanti CM, Carlin AM, Tyburski JG. Incidence of pneumothorax from intercostal nerve block for analgesia in rib fractures. J Trauma. (2001) 51:5369. doi: 10.1097/00005373-200109000-00019

39. Sahu A, Kumar R, Hussain M, Gupta A, Raghwendra KH. Comparisons of single-injection thoracic paravertebral block with ropivacaine and bupivacaine in breast cancer surgery: a prospective, randomized, double-blinded study. Anesth Essays Res. (2016) 10:655-60. doi: 10.4103/0259-1162.191109

40. Bhasin S, Dhar M, Sreevastava DK, Nair R, Chandrakar S. Comparison of efficacy of epidural ropivacaine versus bupivacaine for postoperative pain relief in total knee replacement surgeries. Anesth Essays Res. (2018) 12:2630. doi: 10.4103/aer.AER_134_17

Conflict of Interest: The authors declare that the research was conducted in the absence of any commercial or financial relationships that could be construed as a potential conflict of interest.

Copyright (c) 2021 Chen, Zhu and Du. This is an open-access article distributed under the terms of the Creative Commons Attribution License (CC BY). The use, distribution or reproduction in other forums is permitted, provided the original author(s) and the copyright owner(s) are credited and that the original publication in this journal is cited, in accordance with accepted academic practice. No use, distribution or reproduction is permitted which does not comply with these terms. 